\title{
Visual outcomes and subjective satisfaction quotient of a multifocal intraocular lens in Indian population
}

\author{
Jigyasa Sahu (1)', Sandeep Kumar', Anil D. Mehta² \\ 'Guru Nanak Eye Centre, MAMC, New Delhi, India \\ ${ }^{2}$ PGIMSR and ESI Hospital, Basaidarapaur, New Delhi, India
}

\begin{abstract}
BACKGROUND: The purpose of the study was to compare the visual acuity, contrast sensitivity, subjective visual satisfaction, and spectacle independence in patients implanted with apodized diffractive multifocal versus monofocal intraocular lens following phacoemulsification. This was a 15-months prospective, interventional study.

MATERIAL AND METHODS: In each of the 60 patients enrolled in the study, one eye was operated. In 30 patients, we implanted monofocal intraocular lens (IOLs) (Group I) and in 30 consecutive patients - multifocal IOLs (Group II). Follow-up visits at postoperative 1st, 4th, and 6th week were done. Distance and near visual acuity, contrast sensitivity at $3,6,12$, and $18 \mathrm{cpd}$, refractive pseudophakic correction, and visual satisfaction by VF-14 questionnaire were assessed.

RESULTS: Uncorrected and best-corrected distance visual acuity were comparable between the two groups ( $\mathrm{p}>0.05)$. $100 \%$ of patients in group I and $96.66 \%$ in Group II attained best-corrected vision of $\geq 6 / 9$. Uncorrected near visual acuity was significantly better in Group II $(\mathrm{p}<0.0001)$. Sixteen out of 30 patients in Group II achieved unaided $\mathrm{N} 6$ vision. Corrected near vision was similar in the two groups. Mean near correction was much lower $(+0.76$ DS \pm 0.86 ) in Group II. Photopic contrast sensitivity was better in Group I at lower frequencies ( 3 and $6 \mathrm{cpd}$ ). More satisfaction and spectacle independence was seen in Group II.

CONCLUSION: The apodised diffractive multifocal IOLs are a reasonable choice for patients who opt for freedom from glasses and understand its inherent limitation of reducing contrast to some degree.
\end{abstract}

KEY WORDS: multifocal; apodised diffractive; Indian patients; contrast sensitivity

Ophthalmol J 2021; Vol. 6, 143-150

\section{INTRODUCTION}

Multifocal intraocular lenses (IOLs) are designed to overcome the postoperative lack of accommodation by dividing the incoming light onto two or more focal points. One of these is used for distance vision, the other for near or intermediate vision. These IOLs reduce the need for spectacle correction in daily life [1]. However, good refractive outcomes and low residual astigmatism after surgery are crucial to success. Therefore, accurate biometry and good patient selection are the keys to success. 
Additionally, since the light is divided and some light is lost to higher orders of diffraction, patients have reduced contrast sensitivity. The blurred unfocused image will overlay the focused image and can cause the photic phenomenon of halos seen around light sources, especially at night with a larger pupil. These can be disturbing to patients and are the main reason for the explantation of multifocal IOLs. Hence the role of appropriate patient selection cannot be emphasized more. The most critical preliminary considerations are the patient's lifestyle and primary clinical situation of the eye. Patients' personality is essential in estimating the ability to neuroadaptation in cases of postoperative dysphotopsia, patients' glare, and the patients ability to risk a small loss of contrast sensitivity or temporary glare in exchange for a broader range of vision and spectacle free near vision. Patients' needs and preferences also play an important role in choosing the lens to be implanted. This study reports the complete outcome (subjective and objective) of a foldable apodized diffractive multifocal IOL implant vis-a-vis a foldable monofocal IOL implant.

\section{MATERIAL AND METHODS}

A 15-months prospective interventional study was conducted at Employees State Insurance Hospital, New Delhi. One eye was operated in each of the 60 patients enrolled in the study (30 in each group). The study was carried out in accordance with the Declaration of Helsinki. Written informed consent was obtained from all subjects, and the Institutional Review Board approved the protocol. Patients of uncomplicated immature senile cataract in the age group between 45-70 years undergoing phacoemulsification with IOL implantation were included in the study. Exclusion criteria included patients: with preoperative astigmatism $>1$ dioptre, who have been operated for cataract in other eye, with scotopic pupil size less than $2.5 \mathrm{~mm}$, drivers by occupation, with a previous history of ocular trauma or intra-ocular surgeries, with complicated and congenital cataract. A detailed clinical history of patients with complete ophthalmic evaluation was performed preoperatively. Intraocular lens power calculation was done using SRK-T (Sanders Retzlaff Kraff) regression formula.

Patients were given a pamphlet containing the advantages and disadvantages of both monofocal and multifocal IOLs. They were allowed to choose the IOL they wanted to be implanted with. In- formed consent of the patient was taken in every case after explaining the nature of the surgery and the IOL to be implanted, its complications, risks, and the expected visual outcome.

All patients underwent uncomplicated phacoemulsification by the CataRhex 3 machine by Oertli within the bag IOL placement. The multifocal IOL used was a hydrophobic acrylic single piece apodized-diffractive IOL with 360o square edge with aspheric optic (Eyecryl ${ }^{\mathrm{TM}}$ ACTV, Biotech Vision Care Pvt Ltd). The optic size is $6 \mathrm{~mm}$ with an overall size of $13 \mathrm{~mm}$. The angulation is $10 \mathrm{o}$, and the A constant is 118.5 . The near add is $+3.75 \mathrm{D}$. It has a refractive index of 1.46 at $37 \mathrm{deg}$. C. The monofocal IOL used was hydrophobic acrylic single-piece IOL (Alcon AcrySof IQ lens, model SN60WF). The optic size is $6 \mathrm{~mm}$ with an overall diameter of $10.5 \mathrm{~mm}$. The angulation is $10 \mathrm{o}$, and the A constant is 118.2. Uncorrected distant and near visual acuity were recorded on post-operative days: $7^{\text {th }}, 28^{\text {th }}$, and day $42^{\text {nd }}$. Distance visual acuity was measured with Snellen's distance visual acuity chart, and near acuity was tested with the help of Jaegers chart. Both were converted to $\log$ MAR acuity for the statistical analysis. The refractive correction for distance and near and corrected visual acuity were also noted on the same visits. Distance refractive correction was converted to spherical equivalent (SE) for easy comparison and interpretation. Contrast sensitivity was measured using CSV-1000, a standard sine wave grating chart with the best-corrected visual acuity. The self-standardized backlit system automatically initiates and maintains a light level of $85 \mathrm{~cd} / \mathrm{m}^{2}$. It has four spatial frequencies (sizes) and eight levels of contrast. The patient determines the highest contrast sensitivity level (or the lowest contrast threshold) for which grating is seen for each row (A, $\mathrm{B}, \mathrm{C}$, and D ) and reports the presence or absence of gratings. The last correct grating seen for each spatial frequency is plotted on a contrast sensitivity curve. To determine patients' satisfaction, they were asked to complete a standard visual function index questionnaire (VF-14) on their level of satisfaction with vision during activities at near, intermediate, and distance, day and night, and with and without glasses. Scores out of 100 were noted.

Statistical analysis was performed using the mean and standard deviation for quantitative variables. The comparison of quantitative variables over time was performed using repeated-measures analysis of variance (ANOVA). For multiple measurements, Bonferroni correction was applied when 
necessary. An unpaired t-test was used to compare the visual acuity and contrast sensitivity between the two groups. Spectacle independence and visual satisfaction were compared by Chi Square test. All results were presented with $95 \%$ confidence limits. For all statistical tests, a value of $\mathrm{p}<0.05$ was considered to indicate significant differences.

\section{RESULTS}

The majority of the patients in both monofocal (Group I) and multifocal (Group II) were in the range of 56-60 years. There was no statistically significant difference. Both the groups were similar in terms of preoperative distance and near vision. Subject demographics and preoperative characteristics are summarised in Table 1. The majority of the patients in both groups had preoperative best-corrected distance visual acuity (BCDVA) in the range of 6/60-6/24, i.e., $76.67 \%$ patients in Group I and $73.33 \%$ patients in Group II ( $\mathrm{p}=0.38)$. Patients in both groups had preoperative best corrected near visual acuity (BCNVA) in the range of $\mathrm{J} 4$ or worse, i.e., $63.33 \%$ patients in Group I and $80 \%$ patients in Group II ( $\mathrm{p}=0.17)$.

Changes in post-operative visual acuity in multifocal IOL patients were analysed with respect to time and compared with the monofocal IOL patients. Post-operative uncorrected distance visual acuity (UCDVA) in both Group I and Group II shows significant increases from day $7^{\text {th }}$ to day $28^{\text {th }}$ $(\mathrm{p}<0.0001)$ and from day 7 to day $42(\mathrm{p}<0.0001)$, but a statistically insignificant increase from day $28^{\text {th }}$ to day $42^{\text {nd }}$ (Group I: $\mathrm{p}=0.89$; Group II: $\mathrm{p}=0.264$ using Bonferroni's multiple comparison test). There is no statistically significant difference between uncorrected distant visual acuity (Fig. 1A) between Group I and Group II on day $7^{\text {th }}(\mathrm{p}=0.66)$, day $28^{\text {th }}(\mathrm{p}=0.92)$, and day $42^{\text {nd }}(\mathrm{p}=0.62)$. Best-corrected distant visual acuity also showed no difference (Fig. 1B) among the two groups on day $7^{\text {th }}$ $(\mathrm{p}=0.48), 28^{\text {th }}(\mathrm{p}=0.54)$, and $42^{\text {nd }}(\mathrm{p}=0.62)$.

As expected, uncorrected near visual acuity was much better in Group II right from day $7^{\text {th }}$ (Fig. 1C). There was a stark difference between both groups in terms of uncorrected near visual acuity. $53.3 \%$ of patients in Group II achieved an uncorrected near vision of $\mathrm{J} 1$, with $20 \%$ at $\mathrm{J} 2,16.6 \%$ at $\mathrm{J} 6$, and $10 \%$ at J4. On the other hand, the best-achieved uncorrected near visual acuity in Group I was J6 (23.3\%), followed by J10 (23.3\%), and the majority of patients could read only J17 print (53.3\%). On giving required near correction to all patients, the best-corrected near visual acuity was marginally better in Group II on the final follow-up visit $42^{\text {nd }}$ day $(\mathrm{p}=0.28)$ (Fig. 1D).

Refractive distance correction required in both study groups was similar for distance day $42^{\text {nd }}$ $(p=0.397)$, but the mean near correction required was much lower in Group II as compared to Group

\begin{tabular}{|c|c|c|c|}
\hline & Group I n(\%) (monofocal) & Group II n(\%) (multifocal) & p-value \\
\hline Eyes operated & 33 & 33 & \\
\hline Eyes excluded in analysis & 02 & 01 & \\
\hline Lost to follow-up & 01 & 02 & \\
\hline No. of eyes analyzed & 30 & 30 & \\
\hline \multicolumn{4}{|l|}{ Gender } \\
\hline Male & 18 & 20 & 0.59 \\
\hline Female & 12 & 10 & \\
\hline Age distribution & & $7(23.33)$ & \multirow{6}{*}{0.83} \\
\hline $45-50$ & $9(30)$ & $7(23.33)$ & \\
\hline $51-55$ & $5(16.67)$ & $11(36.66)$ & \\
\hline $56-60$ & $10(33.33)$ & $2(6.66)$ & \\
\hline $61-65$ & $1(3.33)$ & $3(9.99)$ & \\
\hline $66-70$ & $5(16.67)$ & & \\
\hline Mean age $\pm S D$ (yrs) & $56.03 \pm 6.89$ & $55.9 \pm 5.83$ & \\
\hline Mean preoperative BCDVA (LogMAR) \pm SD & $0.81 \pm 0.22$ & $0.79 \pm 0.21$ & 0.38 \\
\hline Mean preoperative BCNVA (LogMAR) \pm SD & $0.33 \pm 0.16$ & $0.36 \pm 0.13$ & 0.17 \\
\hline
\end{tabular}

BCDVA — best-corrected distance visual acuity; BCNVA — best corrected near visual acuity; LogMAR — log minimum angle of resolution; SD — standard deviation 
A

Intergroup comparison of uncorrected distant visual acuity in Group I and Group II patlents

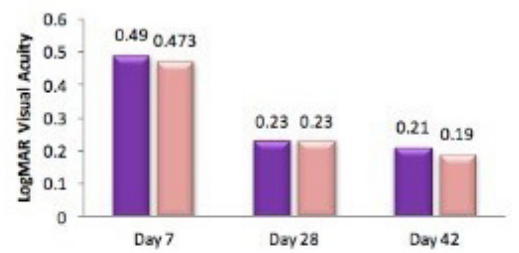

-Group I(Monofocal)

uGroup II (Multfocal)

C

Intergroup comparison of uncorrected near visual acuity in Group I and Group II patlents

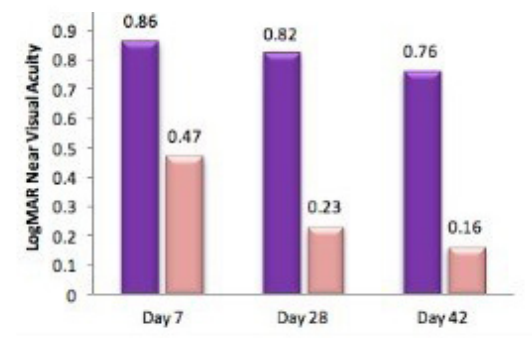

B

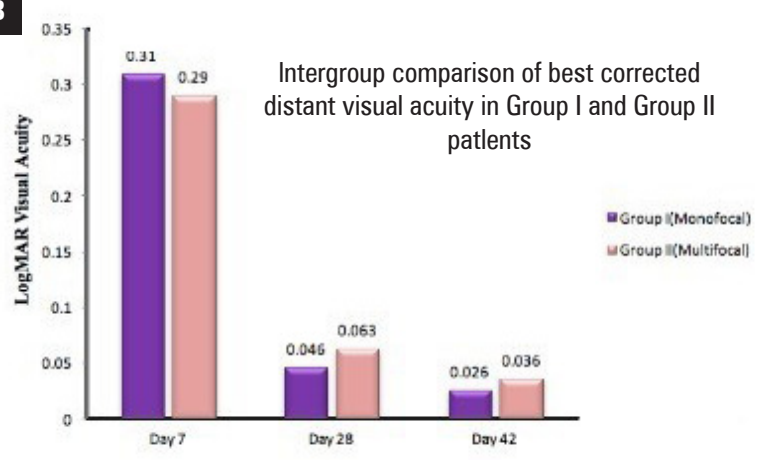

D

Intergroup comparison of best corrected near visual acuity in Group I and Group II patlents

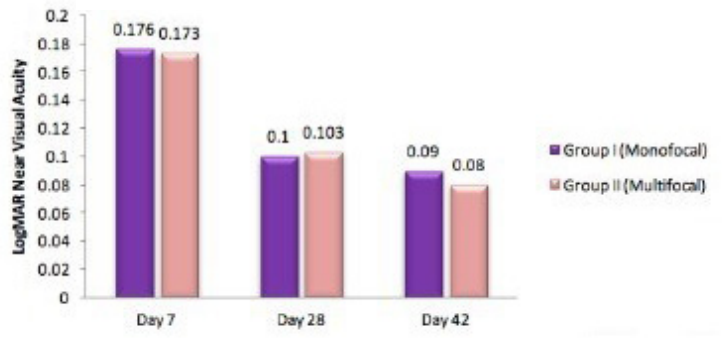

FIGURE 1. A. Intergroup comparison of postoperative uncorrected distant visual acuity in Group I and Group II; B. Intergroup comparison of postoperative best corrected distant visual acuity in Group I and Group II; C. Intergroup comparison of postoperative uncorrected near visual acuity in Group I and Group II; D. Intergroup comparison of postoperative best corrected near visual acuity in Group I and Group II

A Mean distant correction in Group I and Group II patients on all postoperative visits

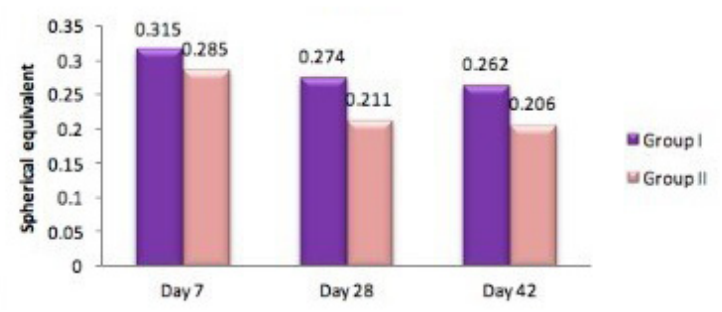

C

Comparison of contrast sensitivity between Group I and Group II on post operative day 42

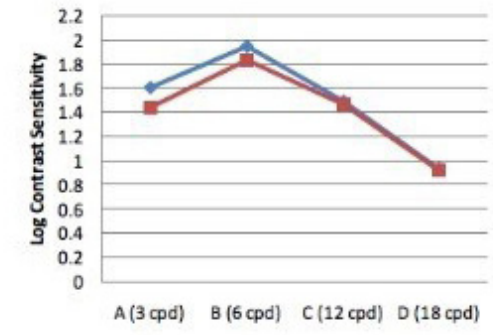

$\rightarrow$ Group I(Monofocal)

- -Group II(Multifocal)
B

Amount of mean near addition for patients of Group I and Group II on all post operative visits

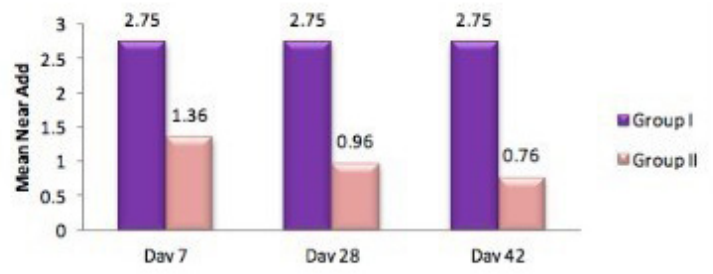

D

Visual function index with and without refractive correction in Group I and Group II patients

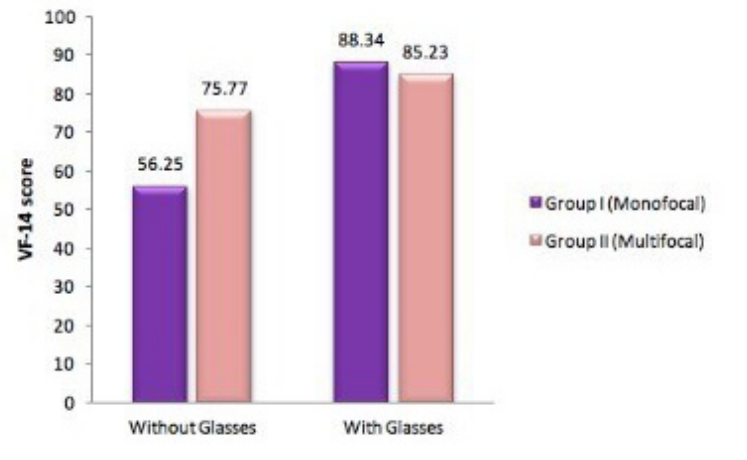

FIGURE 2. A. Intergroup comparison of postoperative mean distant correction required in Group I and Group II; B. Intergroup comparison of postoperative mean near correction required in Group I and Group II; C. Comparison of contrast sensitivity between Group I and Group II on postoperative Day $42^{\text {nd }} ;$ D. Visual function index with and without glasses in Group I and Group II 


\begin{tabular}{|c|c|c|c|}
\hline & Group I (monofocal) & Group II (multifocal) & $\mathrm{p}$-value \\
\hline \multicolumn{4}{|c|}{$\begin{array}{l}\text { Mean postoperative UCDVA } \\
(\text { LogMAR } \pm \text { SD }\end{array}$} \\
\hline Day $7^{\text {th }}$ & $0.49 \pm 0.139$ & $0.473 \pm 0.153$ & 0.66 \\
\hline Day $28^{\text {th }}$ & $0.23 \pm 0.112$ & $0.23 \pm 0.144$ & 0.92 \\
\hline Day $42^{\text {nd }}$ & $0.21 \pm 0.123$ & $0.19 \pm 0.132$ & 0.62 \\
\hline \multicolumn{4}{|c|}{$\begin{array}{l}\text { Mean postoperative BCDVA } \\
(\text { LogMAR) } \pm \text { SD }\end{array}$} \\
\hline Day $7^{\text {th }}$ & $0.31 \pm 0.115$ & $0.29 \pm 0.106$ & 0.48 \\
\hline Day $28^{\text {th }}$ & $0.046 \pm 0.086$ & $0.063 \pm 0.118$ & 0.54 \\
\hline Day $42^{\text {nd }}$ & $0.026 \pm 0.069$ & $0.036 \pm 0.085$ & 0.62 \\
\hline \multicolumn{4}{|c|}{$\begin{array}{l}\text { Mean postoperative UCNVA } \\
(\text { LogMAR) } \pm \text { SD }\end{array}$} \\
\hline Day $7^{\text {th }}$ & $0.86 \pm 0.191$ & $0.47 \pm 0.136$ & $<0.0001$ \\
\hline Day $28^{\text {th }}$ & $0.82 \pm 0.201$ & $0.23 \pm 0.115$ & $<0.0001$ \\
\hline Day $42^{\text {nd }}$ & $0.76 \pm 0.263$ & $0.16 \pm 0.145$ & $<0.0001$ \\
\hline \multicolumn{4}{|c|}{$\begin{array}{l}\text { Mean postoperative BCNVA } \\
\text { (LogMAR) } \pm \text { SD }\end{array}$} \\
\hline Day $7^{\text {th }}$ & $0.176 \pm 0.085$ & $0.173 \pm 0.078$ & 0.87 \\
\hline Day $28^{\text {th }}$ & $0.1 \pm 0.0$ & $0.103 \pm 0.018$ & 0.32 \\
\hline Day $42^{\text {nd }}$ & $0.09 \pm 0.030$ & $0.08 \pm 0.040$ & 0.28 \\
\hline \multicolumn{4}{|c|}{$\begin{array}{l}\text { Distance correction (SE) } \\
\text { (diopters) } \pm \text { SD }\end{array}$} \\
\hline Day $7^{\text {th }}$ & $0.315 \pm 0.27$ & $0.285 \pm 0.27$ & \\
\hline Day $28^{\text {th }}$ & $0.274 \pm 0.24$ & $0.211 \pm 0.25$ & 0.6770 .3240 .397 \\
\hline Day $42^{\text {nd }}$ & $0.262 \pm 0.25$ & $0.206 \pm 0.25$ & \\
\hline $\begin{array}{l}\text { Near corr } \\
\text { (diopters }\end{array}$ & & & \\
\hline Day $7^{\text {th }}$ & $+2.725 \pm 0.24$ & $+1.36 \pm 0.54$ & $<0.0001$ \\
\hline Day $28^{\text {th }}$ & $+2.725 \pm 0.24$ & $+0.96 \pm 0.77$ & $<0.0001$ \\
\hline Day $42^{\text {nd }}$ & $+2.725 \pm 0.24$ & $+0.76 \pm 0.86$ & $<0.0001$ \\
\hline
\end{tabular}

UCDVA — uncorrected distance visual acuity; BCDVA — best corrected distance visual acuity; UCNVA — uncorrected near visual acuity; BCNVA — best corrected near visual acuity; LogMAR — log minimum angle of resolution; SD — standard deviation; SE — spherical equivalent

I patients ( $\mathrm{p}<0.0001)$ (Fig. 2AB). There is a statistically significant progressive decline in the amount of near correction in Group II patients in successive post-operative visits as seen by repeated measures one-way ANOVA, probably signifying that neuroadaptation plays a role in achieving the best outcome of a multifocal IOL. Table 2 presents a post-operative visual outcome comparison between the two groups.

Contrast sensitivity was tested with the help of the CSV-1000 chart in a background luminance of $85 \mathrm{~cd}$. The mean photopic contrast sensitivity on day $42^{\text {nd }}$ was better for Group I than Group II at all frequencies. It was statistically significant only at $3 \mathrm{cpd}$ and $6 \mathrm{cpd}(\mathrm{p}<0.0001)$. This signified that multifocal IOL patients suffered a decrease in contrast detection patterns when compared to those with monofocal IOL (Fig. 2C). The difference was insignificant at higher frequencies i.e. $12 \mathrm{cpd}$ and 18 cpd $(\mathrm{p}=0.2995, \mathrm{p}=0.523)$. At all frequencies, patients of both groups reported improvement with time (day $7^{\text {th }}$ through $28^{\text {th }}$ ), but the effect stabilised post four weeks with little change after that.

Intragroup comparisons using paired t-test show that the visual function index score increases drastically with glasses compared to not using glasses in the post-operative period in both groups (Group I: $p<0.0001$, Group II: $p=0.0001$ ). The increase is much more in Group I when compared to Group II, showing patients in Group I are much more dependant on glasses than in Group II. The mean VFI score was much higher in Group II pa- 


\begin{tabular}{|c|c|c|c|}
\hline & Group I (monofocal) & Group II (multifocal) & p-value \\
\hline \multicolumn{4}{|l|}{ Contrast sensitivity on day $7^{\text {th }}$} \\
\hline $3 \mathrm{cpd}$ & $1.403 \pm 0.104$ & $1.192 \pm 0.116$ & $<0.0001$ \\
\hline $6 \mathrm{cpd}$ & $1.741 \pm 0.093$ & $1.669 \pm 0.089$ & 0.0034 \\
\hline $12 \mathrm{cpd}$ & $1.231 \pm 0.089$ & $1.193 \pm 0.091$ & 0.105 \\
\hline $18 \mathrm{cpd}$ & $0.714 \pm 0.085$ & $0.651 \pm 0.088$ & 0.0075 \\
\hline \multicolumn{4}{|l|}{ Contrast sensitivity on day $28^{\text {th }}$} \\
\hline $3 \mathrm{cpd}$ & $1.584 \pm 0.077$ & $1.414 \pm 0.093$ & $<0.00001$ \\
\hline $6 \mathrm{cpd}$ & $1.925 \pm 0.093$ & $1.822 \pm 0.062$ & $<0.00001$ \\
\hline $12 \mathrm{cpd}$ & $1.465 \pm 0.081$ & $1.407 \pm 0.092$ & 0.0133 \\
\hline $18 \mathrm{cpd}$ & $0.919 \pm 0.094$ & $0.853 \pm 0.102$ & 0.0116 \\
\hline \multicolumn{4}{|l|}{ Contrast sensitivity on day $42^{\text {nd }}$} \\
\hline $3 \mathrm{cpd}$ & $1.607 \pm 0.065$ & $1.439 \pm 0.089$ & $<0.0001$ \\
\hline $6 \mathrm{cpd}$ & $1.945 \pm 0.088$ & $1.832 \pm 0.075$ & $<0.0001$ \\
\hline $12 \mathrm{cpd}$ & $1.488 \pm 0.078$ & $1.464 \pm 0.097$ & 0.2995 \\
\hline $18 \mathrm{cpd}$ & $0.934 \pm 0.086$ & $0.919 \pm 0.097$ & 0.523 \\
\hline \multicolumn{4}{|l|}{ VF-14 Score } \\
\hline Without glasses & $56.252 \pm 5.09$ & $75.77 \pm 17.5$ & $<0.0001$ \\
\hline With glasses & $88.34 \pm 6.45$ & $85.23 \pm 7.79$ & 0.11 \\
\hline No. of patients requiring distance correction $[n(\%)]$ & $23(76.67 \%)$ & $20(66.67 \%)$ & 0.56 \\
\hline No. of patients requiring near correction [n(\%)] & $30(100 \%)$ & $14(46.67 \%)$ & $<0.0001$ \\
\hline
\end{tabular}

tients when asked about their experience without glasses. Though Group II patients were overall satisfied even without glasses, there was high variability in the response of Group II patients evident by the high standard deviation in responses both with and without glasses (Fig. 2D).

We assessed spectacle independence in the groups and found that none of the patients in Group I were free of near correction, whereas more than half (53.33\%) patients in Group II were free of near correction. ( $p<0.0001)$. Thus all patients in Group I required at least near glasses for daily work, whereas $23.3 \%$ of patients in Group II were totally spectacle independent (near and distance). Table 3 compares contrast sensitivity, subjective satisfaction quotient, and spectacle independence between the two groups.

\section{DISCUSSION}

Restoring unaided full-range functional vision is an ultimate goal after cataract extraction. The aim of comparing newer premium IOLs with the age-old gold standard IOLs is to measure their risk versus benefit ratio and provide data for further betterment in the technology of IOL development. In this study, we have attempted to objectively and subjectively explore many of the critical elements in the optical performance of eyes implanted with an apodized diffractive multifocal IOL.

Our findings elaborated that multifocal IOL was at par with monofocal in terms of providing distant visual acuity. These findings are analogous to the other studies evaluating the multifocal IOLs. Vingolo et al. [2] showed that the multifocal group and monofocal group had similar distance uncorrected and best-corrected visual acuities. Negishi et al. [3] showed $91.9 \%$ of eyes with multifocal IOL and $92 \%$ of eyes with monofocal IOL having a distance uncorrected vision of $\geq 6 / 9$. In their study, Gimbel et al. [4] quoted $74.8 \%$ and $78.2 \%$ of eyes achieved $>6 / 9$ vision in multifocal and monofocal groups, respectively. Similarly, studies conducted by Herbert Weghaupt et al., [5] Mercedes Vaquero et al. [6] Jacobe et al. [7] showed comparable results.

Our observations in the context of near acuity were more favourable than the findings of other studies comparing multifocal and monofocal IOLs. UCNVA of 20/40 (J4) or better (logMAR $=0.30$ or roman test equivalent N10) was achieved in $62.2 \%$ of eyes implanted with multifocal IOL in a study by Negishi et al. [3]. In our study, $73.33 \%$ of patients achieved uncorrected $\log$ MAR near visual acuity of $\leq 0.20$ ( $\mathrm{J} 2$ or better; roman 
test type equivalent N8) on a final post-operative visit. Mercedes Vaquero Ruano[6] reported mean values of $\mathrm{J} 2$ in multifocal IOL group and $\mathrm{J} 5$ (or J6) in monofocal group which is the same as our result. The near addition required in the two groups was significantly different. The mean near addition needed in group I patients was $+2.725 \mathrm{DS} \pm 0.24$ as opposed to a much lower near addition in group II, i.e., +0.76 DS \pm 0.86 ( $\mathrm{p}<0.0001$ statistically significant). Not many studies have objectively compared the amount of distance and near addition required post-operatively in monofocal and multifocal groups. We could infer from these findings that although less correction was required, even patients with multifocal IOL experienced enhanced near vision with some amount of additional near correction. Our result matches with the study by Montes Mico et al. [8] in 2003, which suggested that the contrast sensitivity at a distance and near in the multifocal group improved over time $(\mathrm{p}<.01)$. Both the groups achieved a final contrast sensitivity which is typical for their age. Our results were comparable with the studies conducted by Steinert et al. [9], Bleckman et al. [10], Gimble et al. [4], Kamlesh et al. [11], Vaquero et al. [7], Calladine et al. [12], Yamuchi et al., [13] which reported a reduction in contrast sensitivity with a parallel decrease in quality of vision after implantation of multifocal IOLs. Our findings are consistent with Chiam et al. [14], who observed a lower contrast sensitivity in a multifocal group. Vingolo et al. [2] also had similar results.

Steinert et al. [9] mentioned that contrast sensitivity was lower for the multifocal lenses at all contrast levels, but the difference achieved statistical significance only at very low contrast. This agrees with our result of finding statistical significance only at low frequencies of 3 and $6 \mathrm{cpd}$. In their study, Schmitz et al. [15] also observed a statistically significant reduction in contrast sensitivity in the multifocal group was present only at a lower special frequency of $3 \mathrm{cpd}$.

Contrary to our study Montes Mico et al. [8] found similar contrast sensitivity in two groups, but their study duration was 6 months. This could be true as it has been observed that contrast sensitivity levels improve with the multifocal group over time. The standard VF-14 questionnaire was used to assess the satisfaction quotient of patients. Our finding of a lower aided VFI score in the multifocal group could be owing to poor contrast-related dissatisfaction in these patients.
We tried to sum up the visual performance of multifocal IOL in the Indian population. However, there were certain shortcomings. Patients were followed only for 6 weeks post-operatively. Thus the progress of patients both objectively and subjectively could not be studied over a longer time. Various studies have improved contrast sensitivity of eyes implanted with multifocal IOLs 6 months to 1 year post-operatively. A total sample size of 60 and an individual group size of 30 patients is small to conclusively determine and state various optical phenomena after implantation of such IOLs with special properties. We did not measure the contrast in dim light conditions. It has been shown that the contrast sensitivity after IOL implantation is affected more in the mesopic conditions than in the photopic conditions. We did not compare the glare disability and subjective visual phenomena like colored halos in our patients, which is another significant parameter for analyzing the efficiency of multifocal IOLs.

\section{CONCLUSIONS}

It is universal that there is a definite improvement in the visual acuities of all cataract patients after phacoemulsification and IOL implantation. Standing true to its purpose, the multifocal IOL group patients fared outstandingly well in terms of uncorrected near visual acuities compared to patients with monofocal IOL. In concordance with the findings of many previous studies, our study also found a lower level of contrast sensitivity in patients with multifocal IOL. Still, the difference was only statistically significant at lower frequencies. With time the contrast of both groups improved. The improvement is more in the case of multifocal IOLs. Thus, we can conclude that we can expect improved contrast sensitivities in the multifocal group if followed further in time. The subjective satisfaction of the unaided patients was much more in the multifocal group. Spectacle independence was seen to a large extent in multifocal groups.

Both monofocal and multifocal IOLs have their advantages and disadvantages. Appropriately selected patients can achieve spectacle independence and good visual outcomes at both near and distance with current multifocal IOLs. This begins with proper patient education and individualized weighing of benefits and side-effects of multifocal IOLs. Preoperative clinical evaluation is crucial to post-operative success, given the high sensitivity of 
multifocal IOL functioning to minor ocular aberrations. Despite careful selection and screening, some patients will experience unsatisfactory outcomes due to unique issues with this class of IOLs. Suitable post-operative management of both satisfied and dissatisfied patients will ultimately improve the visual benefits of these IOLs.

\section{Acknowledgements}

None declared.

\section{REFERENCES}

1. Bleckmann H, Schmidt 0 , Sunde $T$, et al. Visual results of progressive multifocal posterior chamber intraocular lens implantation. J Cataract Refract Surg. 1996; 22(8): 1102-1107, doi: 10.1016/s08863350(96)80125-8, indexed in Pubmed: 8915807.

2. Vingolo EM, Grenga $P$, lacobelli $L$, et al. Visual acuity and contrast sensitivity: AcrySof ReSTOR apodized diffractive versus AcrySof SA60AT monofocal intraocular lenses. J Cataract Refract Surg. 2007; 33(7): 1244-1247, doi: 10.1016/j.jcrs.2007.03.052, indexed in Pubmed: 17586381.

3. Negishi K, Nagamoto T, Hara E, et al. Clinical evaluation of a five-zone refractive multifocal intraocular lens. J Cataract Refract Surg. 1996; 22(1): 110-115, doi: 10.1016/s0886-3350(96)80279-3, indexed in Pubmed: 8656347.

4. Gimbel HV, Sanders DR, Raanan MG. Visual and refractive results of multifocal intraocular lenses. Ophthalmology. 1991; 98(6): 881-7; discussion 888, doi: 10.1016/s0161-6420(91)32205-x, indexed in Pubmed: 1866141.

5. Weghaupt H, Pieh S, Skorpik C. Comparison of pseudoaccommodation and visual quality between a diffractive and refractive multifocal intraocular lens. J Cataract Refract Surg. 1998; 24(5): 663-665, doi: 10.1016/s0886-3350(98)80262-9, indexed in Pubmed: 9610450.

6. Vaquero-Ruano M, Encinas J, Millan I, et al. AMO Array multifocal versus monofocal intraocular lenses: Long-term follow-up. J
Cataract Refract Surg. 1998; 24(1): 118-123, doi: 10.1016/s08863350(98)80084-9, indexed in Pubmed: 9494909.

7. Jacobi PC, Dietlein TS, Konen W. Multifocal intraocular lens implantation in pediatric cataract surgery. Ophthalmology. 2001; 108(8): 1375-1380, doi: 10.1016/s0161-6420(01)00595-4, indexed in Pubmed: 11470687.

8. Alfonso JF, Fernández-Vega L, Blázquez Jl, et al. Distance and near contrast sensitivity function after multifocal intraocular lens implantation. J Cataract Refract Surg. 2003; 29(4): 703-711, doi: 10.1016/ s0886-3350(02)01648-6, indexed in Pubmed: 12686237.

9. Steinert RF, Post CT, Brint SF, et al. A prospective, randomized, doublemasked comparison of a zonal-progressive multifocal intraocular lens and a monofocal intraocular lens. Ophthalmology. 1992; 99(6): 853-60; discussion 860, doi: 10.1016/s0161-6420(92)31864-0, indexed in Pubmed: 1630773.

10. Bleckmann H, Schmidt 0 , Sunde T, et al. Visual results of progressive multifocal posterior chamber intraocular lens implantation. J Cataract Refract Surg. 1996; 22(8): 1102-1107, doi: 10.1016/s08863350(96)80125-8, indexed in Pubmed: 8915807.

11. Dadeya $S$, Kaushik $S$. Contrast sensitivity and depth of focus with aspheric multifocal versus conventional monofocal intraocular lens. Can J Ophthalmol. 2001; 36(4): 197-201, doi: 10.1016/s00084182(01)80040-5, indexed in Pubmed: 11428528.

12. Calladine D, Evans JR, Shah S, et al. Multifocal versus monofocal intraocular lenses after cataract extraction. Cochrane Database Syst Rev. 2012(9): CD003169, doi: 10.1002/14651858.CD003169.pub3, indexed in Pubmed: 22972061.

13. Wilkins MR. Randomized Trial of Multifocal Intraocular Lenses versus Monovision after Bilateral Cataract Surgery. Ophthalmology. 2013; 120(12): 2449-2455, doi: 24070808, indexed in Pubmed: 10.1016/j. ophtha.2013.07.048.

14. Chiam PJT, Chan JH, Aggarwal RK, et al. ReSTOR intraocular lens implantation in cataract surgery: quality of vision. J Cataract Refract Surg. 2006; 32(9): 1459-1463, doi: 10.1016/j.jcrs.2006.04.015, indexed in Pubmed: 16931256.

15. Schmitz S, Dick HB, Krummenauer F, et al. Contrast sensitivity and glare disability by halogen light after monofocal and multifocal lens implantation. Br J Ophthalmol. 2000; 84(10): 1109-1112, doi: 10.1136/ bjo.84.10.1109, indexed in Pubmed: 11004093. 